\title{
El DERECHO DE HUELGA EN LA CONSTITUCión CHILENA*
}

\author{
Sergio Gamonal Contreras**
}

RESUMEN: Este trabajo analiza si en la Constitución chilena se encuentra consagrado el derecho de huelga. Para estos efectos, se estudia tanto el origen como la evolución del derecho de huelga, así como su importancia en los sistemas de derechos laborales. Luego se revisan las distintas tesis doctrinarias que postulan la consagración de la huelga en nuestra Constitución, para finalmente construir una teoría unitaria acerca de la vigencia de este derecho en nuestro ordenamiento constitucional. tución.

PALABRAS CLAVE: Huelga, trabajo, derechos fundamentales y consti-

\section{THE RIGHT TO STRIKE IN THE CONSTITUTION OF CHILE}

ABSTRACT: This study analyses whether in the Chilean Constitution it can be found established the right to strike. To this purpose, it studies both the origin and the evolution of the right to strike, and their importance in the systems of labor rights. Then, several doctrinal thesis are reviewed that postulate the establishment of the strike in our Constitution, to finally develop a unified theory about the relevance of this right in our constitutional system.

KEY WORDS: Strike, work, fundamental rights and constitution

Sumario: 1) Introducción. 2) Poder y trabajo: orígenes y evolución del derecho de huelga. 3) La huelga como derecho fundamental. 4) Hipótesis doctrinales acerca de la consagración constitucional de la huelga en Chile. (4.1) Tesis restrictiva. (4.2) Tesis del derecho implícito. (4.3) Tesis del bloque de constitucionalidad. (4.4) Tesis dogmática. 5) Conclusiones: una construcción unitaria del derecho de huelga. 6) Bibliografía

Fecha de recepción: 3 de septiembre de 2012.

Fecha de aprobación: 5 de abril de 2013.

** Profesor Derecho del Trabajo, Universidad Adolfo Ibáńez. Correo electrónico:

sergio.gamonal@uai.cl 


\section{1) INTRODUCCIÓN}

La evolución del derecho del trabajo se ha producido sobre dos pilares, el derecho individual y el derecho colectivo. En el derecho individual ha sido fundamental el rol del Estado, a través de la legislación protectora del trabajador. En el derecho colectivo ha sido esencial el rol del sindicato, por medio de la negociación colectiva y del derecho de huelga. El derecho de huelga ha sido el instrumento que ha permitido a los trabajadores negociar de igual a igual frente a sus empleadores. Por ello, no es exagerado decir que el derecho de huelga es la piedra angular del derecho colectivo del trabajo.

Por otro lado, los sistemas laborales oscilan entre tutela individual y colectiva. En países con desarrollo industrial, ambas van surgiendo en paralelo, consolidándose finalmente una tutela individual mínima complementada por una intensa tutela colectiva hasta los ańos setenta. En los países no industriales, tiende a permanecer como principal la tutela individual. En los países de alta industrialización, desde la década de los setenta del siglo pasado, donde las empresas han tendido a deslocalizarse y por lo mismo la cesantía ha ido aumentando, la tutela colectiva decae en parte permaneciendo o incrementándose la protección individual. Este último proceso va acompañado de una pérdida importante de poder por parte de los trabajadores.

Desde esta perspectiva, la pregunta por el derecho de huelga implica interrogarse por el poder real que tienen los trabajadores dentro de la sociedad. Por lo mismo, este derecho se ha desarrollado en los sistemas democráticos, especialmente los europeos, para luego consagrarse en todos los países que se estiman democráticos.

En este ensayo nos preguntaremos por el derecho de huelga en nuestra Constitución. Prima facie es posible advertir que la Constitución contiene solamente una prohibición de huelga en su art. $19 \mathrm{~N}^{\circ} 16^{\circ}$. No obstante, su texto contempla la libertad sindical lo que conlleva una reflexión acerca de su verdadero alcance en el sistema constitucional.

En la doctrina se han ensayado una interpretación restrictiva y tres interpretaciones distintas que concluyen lo mismo, el derecho de huelga en Chile tiene rango constitucional. En este artículo trataremos de construir una visión unitaria del derecho de huelga.

En los capítulos siguientes, revisaremos el origen de este derecho y su actual estado de evolución, para más adelante estudiar las diversas hipótesis mencionadas y ensayar una noción unitaria de huelga en la Constitución. 


\section{2) PODER Y TRABAJO: ORÍGENES Y EVOLUCIÓN DEL DERECHO DE HUELGA}

No constituye una novedad decir que el trabajo constituye un elemento vital en la vida de las personas y que la relación de trabajo se basa en una relación de poder ${ }^{1}$. Desde los inicios de la disciplina laboral, los autores han destacado la relación de poder que subyace al contrato de trabajo. Scelle, al describir el nuevo derecho obrero, a principios del siglo pasado, se refería a esta asimetría de poder ${ }^{2}$. En este mismo sentido Sinzheimer enfatizaba que el derecho del trabajo se aleja de la noción abstracta de persona para aproximarse a la noción concreta de hombre necesitado $^{3}$. Muchos años después, Kanh-Freund manifestaba que el objetivo principal del derecho del trabajo es regular, reforzar y limitar el poder de los empresarios y el poder de las organizaciones de trabajadores ${ }^{4}$. Incluso la doctrina ha llegado a hablar de la existencia de una "dictadura contractual" en la relación de trabajo ${ }^{5}$.

En años recientes, se ha hecho presente cómo este poder no se limita a las formas de trabajar y producir, sino que incluye aspectos tales como las vestimentas que el trabajador puede usar, afectando el derecho de autoimagen y la autorrealización personal de los trabajadores, limitándose, además, la diversidad cultural y religiosa ${ }^{6}$. Por otra parte, se ha destacado cómo la concentración de poder en empresas transnacionales ha afectado gravemente el poder de los sindicatos y la posibilidad de que los trabajadores expongan sus puntos de vista ${ }^{7}$.

1 Sobre la importancia del Trabajo como medio de autorrespeto, como fuente de estructura y orden en la vida cotidiana y como vehículo de autorrealización, véase ELSTER, Jon (2003). "Desempleo y Justicia Local". Revista Internacional de Sociología, N³4, pp. 169-185, pp. 169 a 173.

$2 \quad$ Scelle, Goerges (1922) Le Droit Ouvrier. París: Librairie Armand Colin, 210 pp., p. 2.

3 Sinzheimer, Hugo (1984) Crisis Económica y Derecho del Trabajo. Traducción de Felipe Vázquez Mateo. Madrid: Instituto de Estudios Laborales y de la Seguridad Social, 131 pp., p. 72 .

4 Kahn-Freund, Otto (1987) Trabajo y Derecho. Traducción de Jesús M. Galiana Moreno. Madrid: Ministerio de Trabajo y Seguridad Social, 482 pp., p. 49.

5 Palma Ramalho, María do Rosario (2000) Da Autonomia Dogmática do Directo do Trabalho. Coimbra: Almedina, 1139 pp., p. 247.

6 KLARE, Karl (1994). "Abbigliamento e potere: Il controllo sull'aspetto del lavoratore subordinato". Giornale di Diritto del Lavoro e di Relazioni Industriali, N 63, pp. 567-626, pp. 569 y 570.

7 Atleson, James B. (1985). "Reflections on Labor, Power, and Society". Maryland Law Review, No 44, pp. 841-872, pp. 842 y ss. y 856 y ss.

En el caso de USA y Gran Bretaña, de decadencia sindical, algunos autores han destacado cómo un aumento de la sindicalización podría colaborar en diversos ámbitos como el regulatorio o educacional, véase White, Stuart (1998). “Trade Unionism in a Liberal State”. En Gutmann, Amy (editor): Freedom of Association. Princeton: Princeton University Press, pp. 330-356, pp. 338 y ss. 
En este contexto, de una fuerte subordinación del trabajador, el derecho de huelga y las medidas de autotutela en general se configuran como un reequilibrio mínimo de fuerza entre empleadores y trabajadores. La autotutela sindical ha sido definida como "la acción de los propios trabajadores tendiente a la protección de sus derechos e intereses, sea para garantizar el cumplimiento de las normas vigentes, sea para obtener un progreso en el nivel de protección actual"8. Esta autotutela comprende distintos tipos de acciones o manifestaciones de descontento, como una marcha, una olla común, o una declaración pública.

Se ha enfatizado por la doctrina que la ley sindical no basta para proteger al trabajador. Esta debe ir siempre acompañada por un poder real de los trabajadores, por medio de la autotutela colectiva o sindical. KahnFreund explicaba que una completa negación o una restricción muy severa de la libertad de huelga puede ser un indicador de que la libertad sindical solo existe sobre el papel ${ }^{9}$. En el mismo sentido, Giugni manifestaba que el derecho de huelga permite que la libertad de organización cuente con un instrumento de efectividad bastante potente, dado que el derecho de huelga permite la existencia y actuación la de la organización sindical dentro de un sistema económico de mercado ${ }^{10}$.

Por su parte, la doctrina precisa que para evolucionar desde la libertad individual de asociación a un sistema de convenios colectivos debe aceptarse necesariamente el derecho a la huelga, ya que, de no ser así, las negociaciones sobre convenios colectivos representarían, en palabras del Tribunal Federal Alemán, tan solo una "petición colectiva de limosna"11. Incluso un economista clásico como Stuart Mill estaba a favor de los sindicatos y de la huelga, como único medio de los que venden su trabajo para cuidar de sus intereses en un sistema de libre competencia ${ }^{12}$. Para Stuart Mill la amenaza de huelga permite a los trabajadores exigir una participación en las ganancias del trabajo que venden. En este contexto, para este autor la huelga es una parte valiosa de la maquinaria social existente ${ }^{13}$.

El conflicto industrial o de trabajo puede ser visto desde la óptica jurídica como una anomalía o patología que es necesario suprimir. O se lo puede ver más positivamente, donde el derecho cumple un rol de canali-

\footnotetext{
8 Ermida Uriarte, Óscar (1986) Apuntes sobre la Huelga. Montevideo: Fundación de Cultura Universitaria, 187 pp., p. 9.

9 Kahn-Freund (1987) 389.

10 Giugni, Gino (1997) Diritto sindacale. Bari: Cacucci, 302 pp., p. 225.

11 Däubler, Wolfgang (1994) Derecho del Trabajo. Madrid: Centro de Publicaciones Ministerio de Trabajo y Seguridad Social, 1021 pp., p. 237.

12 Mill, John Stuart (1943) Principios de Economía Politica. Traducción de la Edición Ashley de 1909 (la séptima edición de 1871 fue la última corregida por Mill) de Teodoro Ortiz. México: Fondo de Cultura Económica, 1031 pp., p. 924.

13 Mill (1943) 925.
} 
zarlo y no de represor de dicha situación. Para esta perspectiva, el conflicto es consustancial a la sociedad industrial y no puede ser eliminado en forma artificial ${ }^{14}$. En los países desarrollados se impuso, sobre todo luego de la Segunda Guerra Mundial, este último modelo bajo la denominación de "pluralismo conflictual", reconociendo al conflicto como una característica esencial de la sociedad y considerándolo como un valor positivo, institucionalizándolo como medio de integración y de progreso del sistema social ${ }^{15}$.

Para canalizar el conflicto es preciso institucionalizarlo, a saber, permitir su expresión dentro de un cierto contexto regulatorio ${ }^{16}$. Para cumplir este objetivo deben existir ciertas condiciones: a) el conflicto no debe ser tan radical que atente contra la identidad del sistema; b) el conflicto no debe ser permanente y la utilización de los medios de lucha, especialmente la huelga, no debe ser exagerado, y c) el Estado debe contar con un grado suficiente de legitimación y fuerza política para realizar dos tareas: (1) fijar normas sustanciales y de procedimiento a fin de regular el conflicto y controlar el ejercicio del poder social de los grupos para garantizar todas las libertades individuales, y (2) poder cumplir en la esfera social un rol de mediador del conflicto, así como de propulsor y coordinador de la actividad de los grupos hacia objetivos de interés general ${ }^{17}$.

Las modalidades en que tiende a manifestarse el conflicto industrial son expresión de fuerza entre trabajadores y empleadores. La fuerza dentro del conflicto industrial, más que buscar la destrucción del adversario persigue doblegar su voluntad e imponer el propio punto de vista ${ }^{18}$. Por parte del empleador, las potestades que el ordenamiento jurídico le reconoce y la subordinación del trabajador permiten que ejerza constantemente esta fuerza y que sea una fuerza revestida de legalidad. Estas potestades del empleador pueden ser utilizadas como medidas de fuerza, por ejemplo, a través de los despidos ${ }^{19}$, de sanciones disciplinarias, por la denegación de ascensos, uso del jus variandi, etc. Son pocas las acciones del empleador genuinamente conflictivas, como las listas negras o el cierre

14 Cedrola Spremolla, Gerardo (1998) Ensayo sobre la Paz Social. Montevideo: Fundación de Cultura Universitaria, 162 pp., p. 21.

15 Mengoni, Luigi (1985). "Gruppi organizzati e mediazioni dei conflitti". En Diritto e Valori. Bolonia: Il Mulino, pp. 307-332, p. 308.

Cedrola (1998) 22.

Mengoni (1985) 308 a 310.

Cedrola (1998) 25.

Sobre el despido como acto de violencia, véase Baylos, Antonio y Pérez Rey, Joaquín (2009) El Despido o la Violencia del Poder Privado. Madrid: Trotta, 199 pp., pp. 44 y ss. y véase también el prólogo a este libro de U. Romagnoli publicado además en Romagnoli, Umberto (2008). "Sobre el despido o la Violencia del Poder Privado". Revista de Derechos

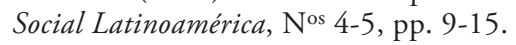


patronal ${ }^{20}$. Por el contrario, las medidas conflictivas de los trabajadores, considerando que se encuentran subordinados al empleador, siempre son directas y conflictivas y, por lo mismo, costosas. Es por ello que se ha definido a la huelga como "un uso mínimo de fuerza" frente a las numerosas potestades del empleador ${ }^{21}$.

Se ha destacado que la huelga tiene una naturaleza polimorfa, como derecho de la persona, como derecho natural, como derecho social, como hecho social que va más allá de las relaciones laborales regulares y como hecho político. Por tanto su regulación se interrelaciona en forma directa con la dinámica social ${ }^{22}$.

La huelga antecede al derecho del trabajo, entendida como un fenómeno social, en esencia revolucionario, que busca expresar el rechazo frente al modelo social dominante. Por ello, podemos decir que las primeras huelgas datan del siglo XV a.C. en Egipto ${ }^{23}$. La novedad es que el derecho del trabajo la reconoce jurídicamente ${ }^{24}$, transformándola en un derecho fundamental.

Para Ermida la huelga es un instrumento de la libertad sindical ${ }^{25}$ y "consiste en un instituto típico del derecho colectivo que procura efectivizar, precisamente, la autotutela laboral y la libertad sindical" 26 . Su ejercicio es visto como uno de los instrumentos principales para suprimir las desigualdades de hecho que impiden el desarrollo de las personas y la participación social de los trabajadores ${ }^{27}$.

La huelga representa una nueva concepción de la democracia, la democracia social, que complementa la noción tradicional de democracia y se fundamenta en la noción de igualdad ${ }^{28}$. Para Baylos el ejercicio de la huelga resulta paradójico si consideramos que implica un rechazo al trabajo dependiente que, precisamente, permite reivindicar la centralidad de

20 Ermida Uriarte, Óscar (1999) La Flexibilización de la Huelga. Montevideo: Fundación de Cultura Universitaria, 55 pp., p. 24.

21 Gamonal Contreras, Sergio (2011) Derecho Colectivo del Trabajo. 2a edición. Santiago de Chile: Abeledo Perrot, 521 pp., p. 364.

22 Pierri, Maurizia (2008) Lo Sciopero nella Democrazia Deliberativa. San Cesario di Lecce: Pensa Editore, 125 pp., p. 76.

23 Radé, Christophe (1997) Droit du Travail et Responsabilité Civile. París: LGDT, 397 pp., p. 248.

24 Podemos agregar que los primeros reconocimientos jurídicos de la huelga, consistentes a su prohibición y posterior sanción también son anteriores al derecho del trabajo, por ejemplo, las Ordenanzas de Colbert de 1660. Véase Radé (1997) 248.

25 ERMIDA (1986) 10.

26 ERMIDA (1986) 9.

27 Vallebona, Antonio (2007) Le Regole dello Sciopero nei Servizi Pubblici Essenziali. Turín: Giappichelli, 197 pp., p. 11.

28 Del Punta, Riccardo (2007). "Lo Siopero". En Bessone, Mario (director): Il Lavoro Subordinato. Trattato di Diritto Privato, Vol. XXIV-T. I. Turín: Giappichelli, pp. 393-436, p. 395. 
este tipo de trabajo en la sociedad democrática. La huelga crea un espacio de visibilidad al trabajo en sociedad ${ }^{29}$.

Una definición clásica de huelga la conceptúa como una "abstención colectiva de trabajo" 30 . Esta definición ha sido superada por la realidad lo que ha llevado a la doctrina a proponer una noción mucho más amplia de huelga, comprensiva de todo tipo de perturbación del proceso productivo $^{31}$. Estos tipos más contemporáneos de huelga incluyen incluso perturbaciones que implican trabajar, como las huelgas de celo, de trabajo lento, de hipertrabajo y de pensamiento.

Se ha hablado de límites internos y externos a la huelga. Los primeros, se refieren a la definición del derecho de huelga y los segundos a su armonía respecto de los demás derechos fundamentales ${ }^{32}$. La doctrina ha tendido a ampliar la eficacia del derecho de huelga, rechazando los límites internos y centrándose solo en los externos ${ }^{33}$.

En cuanto a sus fines, la huelga no solo implica un fin económico o patrimonial vinculado a los intereses profesionales de los trabajadores (huelga económica o con fines contractuales ${ }^{34}$ ). También la huelga puede propender a defender a los trabajadores frente a un incumplimiento legal o contractual del empleador. Además, hacia fines del sesenta y comienzos de los setenta el movimiento sindical está en su apogeo en Europa y su principal instrumento, el derecho de huelga, no solo representa los intereses económicos del grupo trabajador sino que pasa a ser un derecho que actúa los intereses de los trabajadores en general, abarcando objetivos económicos y sociales en sentido amplio. En este contexto resulta legítimo incluso el derecho a la huelga política ${ }^{35}$.

También se han aceptado las denominadas huelgas de solidaridad, o sea, cuando los trabajadores van a huelga para apoyar y solidarizar con otros trabajadores de otras empresas. Aunque se trate de trabajadores de distintas unidades productivas, esta huelga se basa en la comunidad de intereses de los trabajadores en conflicto ${ }^{36}$.

\footnotetext{
29 Baylos Grau, Antonio (2011). "Estado Democrático de Derecho y amplio reconocimiento del Derecho de Huelga”. Derecho Laboral, N²42, pp. 285-292, p. 286.

30 Gamonal (2011) 369 y Novitz, Tonia (2003) International and European Protection of the Right to Strike. Nueva York: Oxford University Press, 419 pp., p. 6.

ERmida (1999) 48 y Gamonal (2011) 370.

Giugni (1997) 241 y ss.

Pizzuti, Paolo (2010) Sciopero Articolato e Prestazioni Improduttive. 2a edición. Roma: Aracne Editrice, 207 pp., p. 9.

34 Bellomo, Stefano (1998). "Lo Sciopero". En Santoro Passarelli, Giuseppe (editor): Diritto del Lavoro e della Previdenza Sociale. Il lavoro privato e pubblico. 2a edición. Assago: IPSOA Editore, pp. 1149-1172., p. 1154.

35 Baylos Grau, Antonio (1991) Derecho del Trabajo: Modelo para Armar. Madrid: Trotta, 158 pp., p. 51.

36 Bellomo (1998) 1154
} 


\section{3) LA HUELGA COMO DERECHO FUNDAMENTAL}

Hablar de la huelga como derecho fundamental implica estudiarla tanto desde el derecho constitucional como internacional.

No siempre se ha reconocido este estatus al derecho de huelga. Como precisaba Calamandrei su evolución se ha caracterizado por una legislación en tres etapas o fases, primero la prohibición, luego la tolerancia y finalmente su consagración como derecho ${ }^{37}$. La prohibición negaba el conflicto e implicó la persecución penal de la huelga ${ }^{38}$. La tolerancia implica que ya no es delito pero tampoco un derecho. La huelga puede implicar despido de los trabajadores así como indemnizar los daños producidos al empresario. Incluso, juristas como Barassi y Carnelutti defendieron que frente a un conflicto, el empleador incluso podía despedir a aquellos trabajadores que no adhirieron a la huelga ${ }^{39}$. Cuando la huelga se consagra como derecho, se permite que tanto el sindicato como los trabajadores no sean objeto de responsabilidad por la misma, siempre y cuando respeten el marco legal existente ${ }^{40}$. Un paso más se concreta durante el siglo XX, al estimarse que la huelga constituye un derecho fundamental ${ }^{41}$.

$\mathrm{Al}$ referirnos a la huelga como derecho fundamental debemos detenernos en la noción de libertad sindical. La libertad sindical comprende el derecho de sindicarse, de negociar colectivamente y el derecho de huelga. Esta tríada constituye el núcleo duro de la libertad sindical y es su piedra angular. De la Cueva destacaba lo anterior al referirse a la visión triangular del derecho colectivo del trabajo, donde se conforma un triángulo equilátero con tres lados iguales: sindicatos, negociación y huelga. Si falta algunos de estos lados ya no hay triángulo y el sistema se desconfigu$\mathrm{ra}^{42}$.

37 Naimoli, Simona (2008). "Individuale e collettivo in materia di sciopero alle origini del diritto del lavoro". En Loffredo, Antonio (editor): La Titolaritá del Diritto di Sciopero. Bari: Cacucci, pp. 107-116, p. 107.

38 De más está decir que este tipo de prohibiciones penales fueron bastante poco efectivas. En efecto, el derecho penal es eficaz cuando constituye un recurso excepcional, pero es incapaz de hacer frente a conductas masivas. Véase SÁnchez Martínez, M. Olga (1997) La Huelga ante el Derecho. Conflictos, valores y normas. Madrid: Dykinson, 326 pp., p. 293.

39 Naimoli (2008) 110 y 111.

40 El considerar la huelga como delito o como derecho, implica resaltar su aspecto o carácter colectivo (de abstención colectiva de trabajo). Por el contrario, en la etapa de la tolerancia, se destaca su aspecto individual, vinculado a la idea de incumplimiento contractual. Véase SÁNCHEZ (1997) 115.

41 Sobre el valor simbólico y estratégico de reconocer un derecho como derecho fundamental, véase Champeil-Desplats, Véronique (1995). "La notion de droit <<fondamental > et le droit constitucionel français”. En Recueil Dalloz Sirey, Chronique, pp. 323-329, pp. 326 y ss.

42 De la Cueva, Mario (1994). "La Situación Laboral de los Trabajadores Públicos". En De la Cueva, Mario e Izquierdo, Ana Luisa (recopiladores) El humanismo Jurídico de Mario de la Cueva. México: Fondo de Cultura Económica, pp. 653-686, pp. 675 y ss. 
Esta visión triangular es prácticamente unánime en doctrina, en el sentido de que la libertad sindical no puede ser semántica o meramente organizativa, caso en el cual sería indistinguible del derecho de asociación. Su plus implica la posibilidad de negociar y esta idea alude a una paridad de poder que solo se obtiene por vía del derecho de huelga de los trabajadores ${ }^{43}$.

La doctrina ha hecho presente la esencialidad de la libertad sindical no solo como derecho fundamental, sino como prerrequisito o condición para el ejercicio de otros derechos ${ }^{44}$, al igual que la libertad de expresión. Cabe recordar que la consolidación de los derechos sociales se ha fundado en el derecho de huelga ${ }^{45}$.

Muchas constituciones reconocen expresamente el derecho de huelga, por ejemplo la de Italia, la de Francia y la de España. Cabe recordar que la primera constitución en este sentido fue la de los Estados Unidos Mexicanos de 1917, en su art. 123 A XVII, aún vigente, con el texto siguiente: "Las leyes reconocerán como un derecho de los obreros y de los patronos, las huelgas y los paros". Luego, los apartados XVIII y XIX desarrollan esta consagración.

En América Latina casi todas las constituciones consagran "expresamente" la huelga como derecho. Llama la atención el caso de la Cuba que nada dice y el de Chile que la prohíbe en el sector público y en los servicios esenciales ${ }^{46}$. Por tanto el derecho de huelga encuentra consagración constitucional explícita en numerosos países de nuestro continente, a saber, Argentina (art. 14 bis), Bolivia (art. 159), Brasil (art. 9), Colombia (art. 56), Costa Rica (art. 61), Ecuador (art. 326 N $^{\circ} 14$ ), El Salvador (art. 48), Guatemala (art. 104), Honduras (art. $128 \mathrm{~N}^{\circ} 13$ ), Nicaragua (art. 83), Panamá (art. 69), Paraguay (art. 98), Perú (art. $28 \mathrm{~N}^{\circ} 3$ ), Puerto Rico (Sección 18 Art. II), República Dominicana (art. 62 N6), Uruguay (art. 57) y Venezuela (art. 97).

Incluso en aquellos casos en que las constituciones no estatuyen una consagración expresa de la libertad sindical, se ha interpretado que la libertad de asociación constitucional conlleva también respecto de los trabajadores la posibilidad de recurrir a la huelga, por ejemplo, en Alemania,

43 Véase White (1998) 352 nota 10. Este autor ha justificado que el Estado liberal tiene el deber de promocionar los sindicatos, si se es consecuente con el pensamiento de Locke y Rawls. Véase White, Stuart (2012). "Liberal Neutrality and Trade Unions”. Comparative Labor Law \& Policy Journal, Vol. 33, pp. 417-426, pp. 419 y ss.

44 Ermida Uriarte, Óscar (2011). "Crítica de la Libertad Sindical”. Derecho Laboral, N²42, pp. 225-253, p. 227.

45 Baylos (2011) 286.

46 Rodríguez-Piñero y Bravo Ferrer, Miguel y Villavicencio Ríos, Alfredo (1995). "La Libertad Sindical en las Constituciones Latinoamericanas”. En Ermida Uriarte, Óscar y Ojeda Avilés, Antonio (coordinadores): El Derecho Sindical en América Latina. Montevideo: Fundación de Cultura Universitaria, pp. 11-38, pp. 35 y ss. 
Bélgica, Holanda, Dinamarca y Luxemburgo ${ }^{47}$. Lo mismo en el caso de la Corte Europea de Derechos Humanos ${ }^{48}$.

En el mismo sentido se ha pronunciado la Corte Interamericana de Derechos Humanos al reconocer que la libertad de asociación, en materia sindical, reviste la mayor importancia para la defensa de los intereses legítimos de los trabajadores y se enmarca en el corpus juris de los derechos humanos ${ }^{49}$. Se trataba de un caso que afectaba a Panamá, donde habían sido despedidos 270 trabajadores en el sector público luego de una huelga ilegal. Al respecto, la Corte manifestó que: "La libertad de asociación, en materia sindical, consiste básicamente en la facultad de constituir organizaciones sindicales y poner en marcha su estructura interna, actividades y programa de acción, sin intervención de las autoridades públicas que limite o entorpezca el ejercicio del respectivo derecho. Por otra parte, esta libertad supone que cada persona pueda determinar sin coacción alguna si desea o no formar parte de la asociación. Se trata, pues, del derecho fundamental de agruparse para la realización común de un fin lícito sin presiones o intromisiones que puedan alterar o desnaturalizar su finalidad" 50 .

Es interesante este caso, porque Panamá había alegado expresamente que el derecho de huelga no forma parte del derecho de asociación consagrado en el art. 16 de la Convención Americana de Derechos Humanos, Pacto San José de Costa Rica, de $1969^{51}$. Pero la Corte tuvo una opinión distinta, en el sentido de que la medida gubernamental "afectó el ejercicio del derecho a la libertad de asociación sindical en general (uno de cuyas expresiones es el derecho de huelga)" 52 , por lo que el despido de los trabajadores había sido desproporcionado y Panamá había violado el derecho a la libertad de asociación y por ello debía reintegrar a los trabajadores,

47 Di Cerbo, Fernando (1983). "Il diritto del lavoro dei paesi dell'Europa continentale partecipanti alla CEE”. En Mazzoni, Giuliano (director): Enciclopedia Giuridica del Lavoro, T. I, No 14. Padova: CEDAM, 192 pp., p. 50. Ver, además, Veneziani, Bruno (1992) Stato e autonomia collettiva, diritto sindacale italiano e comparato. Bari: Cacucci, 501 pp., p. 355 y Rémy, Patrick (1998). "Le Contenu de la Liberté de Coalition dans la Constitucion Allemande". Bulletin de Droit Comparé du Travail et de la Sécurité Social, Université Montesquieu - Bordeaux IV, COMPTRASEC, pp. 84-116, p. 94.

48 Se trata del caso Demir and Baykara v. Turkey, en el cual la Corte Europea expresa que el negociación colectiva forma parte esencial de la libertad de asociación. Luego, en Enerji Yapi-Yol Sen v. Turkey manifestó que el derecho de huelga es un medio esencial para negociar colectivamente. Véase Leader, Sheldon (2009-2010). "Can You Derive a Right to Strike from the Right to Freedom of Association?" Canadian Labour \& Employment Law Journal, 15, pp. 271-295, p. 290.

49 Corte Interamericana de Derechos Humanos. 2 de febrero de 2001. "Caso Baena, Ricardo y otros vs. Panamá", párrafo 158. Cursivas en el original.

CIDH. Caso Baena, Ricardo y otros vs. Panamá, párrafo 156.

CIDH. Caso Baena, Ricardo y otros vs. Panamá, párrafo 152.

CIDH. Caso Baena, Ricardo y otros vs. Panamá, párrafo 95. 
indemnizar el daño material y moral producido, y reembolsar costas y gastos $^{53}$.

Desde la perspectiva del derecho internacional, cabe destacar la obra de la Organización Internacional del Trabajo (en adelante OIT) desde sus orígenes, dado que, en palabras de Ermida, el preámbulo de la Constitución de la OIT, de 1919, puede ser considerado como la primera declaración internacional de derechos, lo que implicaría que la consagración de los derechos sociales (laborales) habrá precedido la consagración de los derechos civiles y políticos ${ }^{54}$, a lo menos, en el ámbito internacional. Más adelante, al aprobarse el Convenio 87 de la OIT, sobre Libertad Sindical y Protección del Derecho de Sindicación, en junio de 1948 (meses antes de la adopción de la Declaración Universal de Derechos Humanos), la libertad sindical pasa a ser el primer derecho fundamental en estar reconocido, consagrado y regulado en un tratado internacional específico ${ }^{55}$.

Y luego, en 1951 cuando la OIT crea el Comité de Libertad Sindical, nos encontramos frente al primer derecho fundamental que cuenta con un procedimiento internacional de control, especializado y exclusivo ${ }^{56}$.

También es importante mencionar el Convenio No 98, de 1949, sobre la aplicación de los principios del derecho de sindicación y de negociación colectiva; el Convenio No 135, de 1971, relativo a la protección y facilidades que deben otorgarse a los representantes de los trabajadores en la empresa, y el Convenio No 151, de 1978, sobre protección del derecho de sindicación y los procedimientos para determinar las condiciones de empleo en la administración pública. Todos ratificados por nuestro país.

En 1998 la OIT emite la declaración sobre los "Principios y Derechos Fundamentales en el Trabajo", donde se contempla la libertad sindical y el derecho de negociación colectiva como un estándar mínimo aceptable de civilización, que vincula a todos los Estados aun cuando no hayan ratificado los Convenios Fundamentales.

La Declaración Universal de Derechos Humanos establece en su artículo 23 punto 4 el derecho a fundar sindicatos y sindicarse; y la Declaración Americana de los Derechos y Deberes del Hombre consagra en su artículo XXII el derecho de asociarse sindicalmente.

Respecto de los tratados internacionales sobre derechos humanos ratificados por Chile y que se encuentran vigentes, debemos mencionar, además de los Convenios OIT, el Pacto Internacional de Derechos Civiles y Políticos, de 1966 (art. 22), como la Convención Americana sobre

\footnotetext{
53 CIDH. Caso Baena, Ricardo y otros vs. Panamá, párrafos 172, 173, 204, 205, 206, 208 y 214.

$54 \quad$ ERMIDA (2011) 229.

55 ERMida (2011) 230.

56 ERMida (2011) 230.
} 
Derechos Humanos "Pacto de San José de Costa Rica", de 1969 (art. 16). Ambos consagran la libertad sindical.

Por su parte, el Pacto Internacional de Derechos Económicos, Sociales y Culturales, de 1966, también consagra la libertad sindical con una mención expresa al derecho de huelga, ejercido en conformidad a las leyes de cada país (art. 8 1.d).

La OIT considera que el derecho de huelga es corolario indisociable de la libertad sindical ${ }^{57}$ y si bien en los Convenios 87 y 98 de la OIT no se menciona expresamente el derecho de huelga, tanto el Comité de Libertad Sindical como la Comisión de Expertos en Aplicación de Convenios y Recomendaciones han estimado que el derecho de las organizaciones de trabajadores y empleadores de organizar su administración y actividades y de formular su programa de acción (art. 3 del Convenio No 87), consagrando como objeto de dichas organizaciones el fomento y la defensa de los intereses de los trabajadores o de los empleadores (art. 10 del Convenio No 87), implican la posibilidad de recurrir a la huelga como derecho fundamental de los trabajadores y sus organizaciones ${ }^{58}$.

Todos estos instrumentos son muy relevantes considerando la cláusula de apertura que establece el art. $5^{\circ}$, inciso segundo, de nuestra Constitución, y que comentaremos en los párrafos siguientes.

\section{4) Hipótesis doctrinales ACERCA DE LA CONSAGRACIÓN CONSTI- TUCIONAL DE LA HUELGA EN CHILE}

La construcción del derecho de huelga desde la Constitución es de gran importancia jurídica y simbólica. Jurídica, dado que la supremacía constitucional operará respecto de las demás fuentes del derecho e influirá en la interpretación e integración del mismo. Simbólica, dado que implicará su reconocimiento en el máximo nivel normativo.

Se ha destacado que muchas veces las constituciones hacen el "trabajo lindo" de consagrar el derecho de huelga, para que luego el legislador

$57 \quad$ Villavicencio Ríos, Alfredo (2007) La Libertad Sindical en las Normas y Pronunciamientos de la OIT: sindicación, negociación colectiva y huelga. Montevideo: Fundación de Cultura Universitaria, 92 pp., p.79.

58 Gernigon, Bernard; Odero, Alberto y Guido, Horacio (1998) Principios de la OIT sobre el Derecho de Huelga. Ginebra: Oficina Internacional del Trabajo, 64 pp., p. 8. Esta conclusión no es aceptada por el Grupo de los Empleadores dentro de la OIT, porque los Convenios 87 y 98 no mencionan expresamente este derecho. Sin embargo, han estimado que el derecho de llevar a cabo acciones directas (derecho de huelga y cierre patronal) podría posiblemente reconocerse como parte integrante del derecho internacional consuetudinario y en este contexto debería rechazarse la prohibición completa de este derecho o su regulación bajo condiciones excesivamente restrictivas. Véase GeRnigon et al. (1998) 9. 
haga el "trabajo sucio" de limitarlo y hacerlo ineficaz ${ }^{59}$. Sin duda, en un estado constitucional esta asimetría resulta muy poco aceptable.

La Constitución chilena consagra la libertad sindical (art. $19 \mathrm{~N}^{\circ} 19^{\circ}$ ) pero no establece en forma expresa el derecho de huelga ${ }^{60}$. Lo que hace la Constitución, en su artículo 19 No $16^{\circ}$ inciso final, es establecer la siguiente prohibición: "no podrán declararse en huelga los funcionarios del Estado ni de las municipalidades. Tampoco podrán hacerlo las personas que trabajen en corporaciones o empresas, cualquiera sea su naturaleza, finalidad o función, que atiendan servicios de utilidad pública o cuya paralización cause grave daño a la salud, a la economía del país, al abastecimiento de la población o a la seguridad nacional. La ley establecerá los procedimientos para determinar las corporaciones o empresas cuyos trabajadores estarán sometidos a la prohibición que establece este inciso".

Fuera de estas prohibiciones expresas (sector público y servicios esenciales), ¿podemos sostener el rango constitucional del derecho de huelga? Con lo dicho en este trabajo, no debiera haber dudas de que consagrada la libertad sindical, se incorpora automáticamente el derecho de huelga. No obstante, podemos distinguir cuatro posturas distintas: la tesis restrictiva, la del derecho implícito, la del bloque de constitucionalidad y la dogmática.

\section{1) Tesis RESTRICTIVA}

Para los defensores de esta postura la Constitución no contemplaría el derecho de huelga, cuya consagración quedaría entregada al legislador, como un derecho de jerarquía legal ${ }^{61}$. En alguna medida la lacónica y prohibitiva referencia constitucional a la huelga obedecería al propósito de comprimir este derecho lo más posible ${ }^{62}$.

Estimados que esta postura es inadmisible considerando en forma sistemática todo el texto constitucional, en especial los arts. $19 \mathrm{~N}^{\circ} 19^{\circ}$ y $5^{\circ}$ inciso segundo, según expondremos más adelante. La Constitución no puede interpretarse en forma exegética, sin concordancias con el resto de su normativa y esta tesis no se condice con el avance de los derechos

\footnotetext{
59 ERMida (1986) 133.

60 La Constitución de 1925, reformada el año 1971 por la ley No 17.398, reconoció el derecho de huelga en conformidad a la ley.

61 Verdugo, Mario; Pfeffer, Emilio y Nogueira, Humberto (1999) Derecho Constitucional. Tomo I, 2a edición actualizada. Santiago de Chile: Editorial Jurídica de Chile, 375 pp., p. 292, y Vivanco, Ángela (2006) Curso de Derecho Constitucional. Aspectos Dogmáticos de la Carta Fundamental de 1980. Tomo II. Santiago de Chile: Ediciones Universidad Católica de Chile, 555 pp., p. 427.

62 Cea Egaña, José Luis (2004) Derecho Constitucional Chileno. Tomo II. Santiago de Chile: Ediciones Universidad Católica de Chile, 733 pp., p. 439.
} 
humanos y del constitucionalismo occidental en los últimos 100 años, vulnerando gravemente el principio de libertad sindical ${ }^{63}$.

\section{2) TESIS DEL DERECHO IMPLÍCITO}

Los defensores de esta perspectiva señalan que la Constitución contempla tácitamente el derecho de huelga, dado que solo lo prohíbe en ciertos casos y, por ende, en los casos no mencionados sería un derecho ${ }^{64}$.

Concordando con el sentido de esta interpretación, no podemos aceptarla. Deducir derechos fundamentales con el aforismo "a contrario sensu" no es pertinente, salvo que la redacción fuera de tal forma concluyente que pudiera operar este raciocinio. Por ejemplo, decir "la huelga no es un derecho en los siguientes casos: ...”. Pero con la actual redacción e interpretando aisladamente el art. $19 \mathrm{~N}^{\circ} 16^{\circ}$ párrafo final, el legislador perfectamente podría prohibir o no contemplar la huelga en el sector privado y no habría vulnerado este precepto.

\section{3) TeSis DEL BLOQUE DE CONSTITUCIONALIDAD}

Para esta tesis aunque no exista una expresa consagración de la huelga esta sí se contempla por el juego del art. $5^{\circ}$ inciso segundo de la Constitución, en relación a los tratados internacionales de derechos humanos que sí la consagran, a saber, el Convenio 87 y el Pacto Internacional de Derechos Económicos, Sociales y Culturales ${ }^{65}$.

$\mathrm{El}$ art. $5^{\circ}$ inciso segundo de la Constitución dispone que "El ejercicio de la soberanía reconoce como limitación el respeto a los derechos esenciales que emanan de la naturaleza humana. Es deber de los órganos del Estado respetar y promover tales derechos, garantizados por esta Constitución, así como por los tratados internacionales ratificados por Chile y que se encuentren vigentes" 66 .

En los últimos decenios hemos asistido a la ampliación del contenido de las constituciones políticas y a numerosos cambios en los efectos de sus normas, debido a nuevos textos constitucionales, a la sucesión, a partir

\footnotetext{
63 Tapia Guerrero, Francisco (2005) Sindicatos en el derecho chileno del trabajo. Santiago de Chile: LexisNexis, 449 pp., p. 210.

64 Macchiavello Contreras, Guido (1989) Derecho Colectivo del Trabajo. Santiago de Chile: Editorial Jurídica de Chile, 548 pp., p. 443; Irureta Uriarte, Pedro (2006) Constitución y Orden Público Laboral. Un análisis del art. 19 No 16 de la Constitución chilena. Colección Investigaciones Jurídicas No 6. Santiago de Chile: Universidad Alberto Hurtado, 234 pp., p. 187, y CaAmaño, Eduardo y Ugarte, José Luis (2008) Negociación Colectiva y Libertad Sindical, un enfoque crítico. Santiago de Chile: LegalPublishing, 110 pp., p. 79.

65 Irureta (2006) 198.

66 Este inciso fue enmendado por la Ley de Reforma Constitucional $N^{\circ} 18.825$, de 17 de agosto de 1989.
} 
de 1948, de numerosos instrumentos internacionales y regionales, y a desarrollos de la doctrina y la jurisprudencia ${ }^{67}$. Es así como se ha llegado a aceptar la integración de los principios y normas sobre derechos humanos, provenientes de cualquier fuente, en un bloque de la más alta jerarquía y fuerza normativa, tanto en el derecho interno como internacional. Se trata del bloque de constitucionalidad de los derechos humanos, de naturaleza supralegal y supraconstitucional ${ }^{68}$.

En nuestro derecho se ha enfatizado que los derechos humanos adquieren con el mencionado art. $5^{\circ}$ dos formas de institucionalización, por medio de la propia norma constitucional y a través de los tratados internacionales de derechos humanos. Es así como este precepto permite incorporar derechos humanos no contemplados en el texto constitucional ${ }^{69}$. De esta forma, el bloque de constitucionalidad de derechos está compuesto por los derechos asegurados constitucionalmente y los asegurados por los tratados de derechos humanos ratificados por Chile y que se encuentren vigentes ${ }^{70}$. En conformidad con lo señalado, el Tribunal Constitucional, por ejemplo, en un caso de inaplicabilidad de un precepto laboral, ha manifestado que estos tratados "complementan la garantía constitucional de protección sobre el trabajo reconocida en el artículo 19 $\mathrm{N}^{\circ} 16^{\circ}$ de nuestra Constitución" 71 .

Este bloque supera la concepción formal de constitución y, en cierta medida, la elastiza ${ }^{72}$. Se ha enfatizado, además, que el catálogo de derechos fundamentales contemplado es amplio y no se limita solo a los expresamente regulados en el texto constitucional o en los tratados de derechos humanos, dado que el inciso original de la Constitución, antes de la enmienda de 1989, disponía que el ejercicio de la soberanía limitaba con el respeto de los derechos esenciales que emanan de la naturaleza humana. Considerando que la enmienda de 1989 tuvo por objetivo fortalecer la vigencia de los derechos humanos, mal podría interpretarse que

\footnotetext{
67 Barbagelata, Héctor-Hugo (2009) El Particularismo del Derecho del Trabajo y los Derechos Humanos Laborales. 2a edición actualizada y ampliada. Montevideo: Fundación de Cultura Universitaria, 353 pp., p. 219.

68 Barbagelata (2009) 221 y 222.

69 Nogueira Alcalá, Humberto (2001). "Las Constituciones y los Tratados en materia de Derechos Humanos: América Latina y Chile”. Revista de Derecho Público, Vol. 63, pp. 115162 , p. 125.

70 Nogueira (2001) 127.

71 Tribunal Constitucional. 26 de julio de 2011. Rol No 1852-10. "Requerimiento de inaplicabilidad por inconstitucionalidad presentado por el Segundo Juzgado de Letras de Talagante respecto del artículo 26 bis del Código del Trabajo, en los autos laborales RIT 103-10-T.L. sobre denuncia de tutela de derechos fundamentales y cobro de prestaciones e indemnizaciones, sustanciados ante el Segundo Juzgado de Letras de Talagante”, donde el Tribunal Constitucional resolvió, estimando que vulneraba la garantía constitucional de la igualdad ante la ley, transgrediendo también la libertad de trabajo. 
ella disminuyó o limitó a ciertos derechos la norma (los constitucionales y los contemplados en tratados internacionales de derechos humanos $)^{73}$. Por ello, la reforma de 1989 tuvo por objeto el otorgar certeza jurídica al reconocer constitucionalmente ciertos catálogos de derechos humanos, a saber, el de la propia constitución y el de los tratados internacionales ratificados por Chile y que se encuentren vigentes ${ }^{74}$.

El bloque de constitucionalidad también tiene efectos interpretativos, dado que tanto el derecho interno como el derecho internacional convencional de derechos humanos se retroalimentan recíprocamente al tenor del principio favor libertatis, pro cives y pro homine, procurando la interpretación más beneficiosa para las personas y sus derechos esenciales, o restringiendo en el menor grado posible los derechos humanos ${ }^{75}$.

Como se ha enfatizado, el estado constitucional de derecho contemporáneo solo puede entenderse como un estado situado internacionalmente y, por lo mismo, limitado en idéntica perspectiva ${ }^{76}$.

Considerando esta tesis, Silva Bascuñán afirma que la huelga es un derecho constitucional en Chile, dado que se trata de un derecho humano esencial, reconocido por el Pacto Internacional de Derechos Económicos, Sociales y Culturales, y en consideración a lo dispuesto en el art. $5^{\circ}$ inc. segundo de la $\mathrm{CPR}^{77}$.

Nogueira es concluyente al señalar que: "conformando el bloque de constitucionalidad del respectivo derecho, independientemente de la jerarquía que el ordenamiento reconozca a los tratados, e interpretando el derecho y sus atributos de acuerdo al principio favor persona, como ya lo ha reconocido expresamente el Tribunal Constitucional en su jurisprudencia de 2008, puede sostenerse la existencia de un derecho fundamental de los trabajadores a la huelga..."78.

Irureta ha precisado que: "los tratados internacionales ratificados por Chile no dejan lugar a dudas en el sentido de que la huelga constituye un derecho, el cual debe ejercerse en conformidad a la ley"79.

\footnotetext{
73 Medina Quiroga, Cecilia (1996). "Introducción: El Derecho Internacional de los Derechos Humanos”. En Medina Quiroga, Cecilia y Mera Figueroa, Jorge (editores): Sistema Jurídico y Derechos Humanos. $\mathrm{N}^{\circ} 6$ serie publicaciones especiales. Santiago de Chile: Escuela de Derecho Universidad Diego Portales, pp. 27-84, p. 63.

$74 \quad$ Medina (1996) 66.

75 Nogueira (2001) 127.

76 Saiz Arnaiz, Alejandro (1999) La Apertura Constitucional al Derecho Internacional y Europeo de los Derechos Humanos. El artículo 10.2 de la Constitución Española. Madrid: Consejo General del poder Judicial, 302 pp., p. 44.

77 Silva Bascuñán, Alejandro (2010) Tratado de Derecho Constitucional. Tomo XIII. Santiago de Chile: Editorial Jurídica de Chile, 438 pp., p. 308.

78 Nogueira Alcalá, Humberto (2009) Derechos Fundamentales y Garantías Constitucionales. Tomo 3: Derechos Sociales Fundamentales. Santiago de Chile: Centro de Estudios Constitucionales de Chile, Universidad de Talca y Librotecnia, 604 pp., p. 437. IRURETA (2006) 198.
} 


\section{4) TESIS DOGMÁTICA}

El derecho de huelga forma parte de la libertad sindical y, por ende, la pregunta a contestar es si la Constitución consagra la libertad sindical. Por tanto, la discusión se traslada al art. 19 No $19^{\circ}$, que establece inequívocamente la libertad sindical y, aún más, en su párrafo tercero hace referencia explícita a la autonomía colectiva o sindical como derecho constitucional.

Esta autonomía comprende todos los elementos de la libertad sindical (organización, negociación y huelga) ${ }^{80}$, y por tanto la huelga como derecho de los trabajadores está expresamente consagrada en la Constitución ${ }^{81}$.

La libertad sindical debe ser interpretada como derecho fundamental, al tenor del ya mencionado principio pro homine, pro cive, favor libertate, que permita a los sindicatos cumplir su rol protector a través de la negociación colectiva y del derecho de huelga. La libertad sindical debe entenderse atendiendo a su carácter instrumental de defensa de la dignidad del trabajador, que se concreta por medio de las acciones colectivas de los trabajadores.

Resulta interesante destacar que esta línea argumentativa laboral ${ }^{82}$ es seguida también por parte de la doctrina constitucional. Por ejemplo, Silva Bascunán precisa que la autonomía sindical comprende la facultad de los sindicatos de determinarse a sí mismos, organizarse sin autorización previa, obtener personalidad jurídica, adoptar sus estatutos y reglamentos, libertad para realizar su propia actividad por medio de la elección de sus representantes, en base a su financiamiento, fijando su propio programa de acción y eligiendo los medios que estimen convenientes para cumplirlo, y la facultad de disolverse ${ }^{83}$.

En igual forma, Nogueira aclara que el derecho de sindicación constitucional comprende la autonomía de acción sindical para conseguir sus propios fines ${ }^{84}$ y dentro de los derechos colectivos de la sindicación encontramos los que constituyen expresión de los programas de acción adoptados por el sindicato, como la negociación colectiva y el recurso a la huelga ${ }^{85}$. Por tanto, dentro del contenido esencial de la libertad sindical

\footnotetext{
80 Tucker, Eric (2012). "Labor's Many Constitutions (And Capital's Too)”. Comparative Labor Law \& Policy Journal, Vol. 33, pp. 355-377, p. 355.

81 Gamonal (2011) 93 y ss.

82 Gamonal Contreras, Sergio (2000). "La Constitución de 1980 y la Libertad Sindical". Anuario de Derecho del Trabajo y Seguridad Social, No 1, Sociedad Chilena de Derecho del Trabajo y de la Seguridad Social, pp. 69-97, pp. 72 y 73.

Silva Bascuñán (2010). 338.

Nogueira (2009) p. 548.

Nogueira (2009) 551.
} 
está la negociación colectiva, el derecho de huelga y la adopción de medidas de conflicto colectivo ${ }^{86}$.

Asimismo, Bronfman, Martínez y Núñez afirman la naturaleza iusfundamental del derecho de huelga, precisando que si existe libertad sindical y derecho de negociar colectivamente, necesariamente debe haber derecho de huelga ${ }^{87}$.

\section{5) CONCLUSIONES: UNA CONSTRUCCIÓN UNITARIA DEL DERECHO DE HUELGA}

La tesis restrictiva no tiene cabida ante el desarrollo actual de los derechos laborales, constitucionales e internacionales.

Concordando con las conclusiones de la tesis implícita, no podemos aceptar su razonamiento, dado que no es pertinente extraer garantías constitucionales con el argumento a contrario sensu, salvo que la redacción del precepto sea concluyente, por ejemplo, si dijera que la huelga solo será prohibida en el sector público.

A nuestro entender la tesis del bloque de constitucionalidad y la dogmática son correctas, pero deben ser integradas en una perspectiva unitaria. Ambas tesis se vinculan fuertemente, dado que el bloque de constitucionalidad influye en la interpretación del texto constitucional, en este caso de la autonomía sindical contemplada en el art. $19 \mathrm{~N}^{\circ} 19^{\circ}$ de la Constitución. Por tanto, la construcción de un fundamento unitario del derecho de huelga en nuestra constitución podría basarse en la tesis del bloque.

No obstante, estimamos más pertinente construir un fundamento unitario desde la tesis dogmática, dado que, desde la perspectiva del derecho colectivo del trabajo, el derecho de huelga es consustancial a la libertad sindical, por tanto, sea cual sea la fuente de consagración: constitución, tratado, ley, etc., esta libertad implica un contrapeso de poder real de los trabajadores a través del derecho de huelga.

De esta forma y como hemos visto en este trabajo, a la pregunta sobre la consagración constitucional del derecho de huelga debemos responder con una pregunta previa: ¿consagra la Constitución la libertad sindical? Si la respuesta es afirmativa se despeja la pregunta original en el siguiente sentido: el derecho de huelga también se contempla.

Obviamente esta conclusión es reforzada por la tesis del bloque de constitucionalidad, dado que la libertad sindical y sus tres pilares (sindi-

Nogueira (2009) 553.

Bronfman Vargas, Alan; Martínez Estay, José Ignacio y Núñez Poblete, Manuel (2012)

La Constitución Comentada. Parte Dogmática. Doctrina y Jurisprudencia. Santiago de Chile:

Abeledo Perrot, 562 pp. p. 356. 
cato, negociación y huelga) constituyen un derecho fundamental consagrado en tratados internacionales ratificados por Chile y que se encuentran vigentes.

Con todo, la tesis dogmática tiene una ventaja, dado que la consagración literal de la libertad sindical en las constituciones y tratados no es uniforme. Se ocupan diversas redacciones y, de hecho, solo el Pacto Internacional de Derechos Económicos, Sociales y Culturales menciona en forma explícita la huelga. Por ello concluimos que la tesis dogmática tiene una ventaja argumentativa dado que la huelga tendría rango constitucional en Chile incluso en el hipotético caso de que el artículo $5^{\circ}$ inciso segundo no existiera.

Por último, no podemos dejar de mencionar que tanto la tesis del bloque como la dogmática tienen una fuerte incidencia en el actual y limitativo marco legal del derecho de huelga en Chile, sobre todo respecto de su eventual inconstitucionalidad.

\section{6) Bibliografía}

- Atleson, James B. (1985). "Reflections on Labor, Power, and Society". Maryland Law Review, No 44, pp. 841-872.

- Barbagelata, Héctor-Hugo (2009) El Particularismo del Derecho del Trabajo y los Derechos Humanos Laborales. 2a edición actualizada y ampliada. Montevideo: Fundación de Cultura Universitaria, 353 pp.

- Baylos Grau, Antonio (1991) Derecho del Trabajo: Modelo para Armar. Madrid: Trotta, 158 pp.

- Baylos Grau, Antonio y Pérez Rey, Joaquín (2009) El Despido o la Violencia del Poder Privado. Madrid: Trotta, 199 pp.

- Baylos Grau, Antonio (2011). "Estado Democrático de Derecho y amplio reconocimiento del Derecho de Huelga". Derecho Laboral, ${ }^{\circ}$ 242, pp. 285-292.

- Bellomo, Stefano (1998). "Lo Sciopero". En Santoro Passarelli, Giuseppe (editor): Diritto del Lavoro e della Previdenza Sociale. Il lavoro privato e pubblico. 2a edición. Assago: IPSOA Editore, pp. 1149-1172.

- Bronfman Vargas, Alan; Martínez Estay, José Ignacio y Núñez Poblete, Manuel (2012) La Constitución Comentada. Parte Dogmática. Doctrina y Jurisprudencia. Santiago de Chile: Abeledo Perrot, 562 pp.

- Caamaño, Eduardo y Ugarte, José Luis (2008) Negociación Colectiva y Libertad Sindical, un enfoque critico. Santiago de Chile: LegalPublishing, 110 pp.

- Cea Egaña, José Luis (2004) Derecho Constitucional Chileno. Tomo II. Santiago de Chile: Ediciones Universidad Católica de Chile, 733 pp. 
- Cedrola Spremolla, Gerardo (1998) Ensayo sobre la Paz Social. Montevideo: Fundación de Cultura Universitaria, 162 pp.

- Champeil-Desplats, Véronique (1995). "La notion de droit $<<$ fondamental $>>$ et le droit constitucionel français". En Recueil Dalloz Sirey, Chronique, pp. 323-329.

- DÄubler, Wolfgang (1994) Derecho del Trabajo. Madrid: Centro de Publicaciones Ministerio de Trabajo y Seguridad Social, 1021 pp.

- De la Cueva, Mario (1994). "La Situación Laboral de los Trabajadores Públicos". En De la Cueza, Mario e Izquierdo, Ana Luisa (recopiladores): El humanismo Jurídico de Mario de la Cueva. México: Fondo de Cultura Económica, pp. 653-686.

- Del Punta, Riccardo (2007). "Lo Siopero". En Bessone, Mario (director): Il Lavoro Subordinato. Trattato di Diritto Privato, Volumen XXIV-Tomo I. Turín: Giappichelli, pp. 393-436.

- Di Cerbo, Fernando (1983). "Il diritto del lavoro dei paesi dell'Europa continentale partecipanti alla CEE”. En Mazzoni, Giuliano (director): Enciclopedia Giuridica del Lavoro, tomo I, No 14. Padova: CEDAM, 192 pp.

- Elster, Jon (2003). "Desempleo y Justicia Local". Revista Internacional de Sociología, $\mathrm{N}^{\circ} 34$, pp. 169-185.

- Ermida Uriarte, Óscar (1986) Apuntes sobre la Huelga. Montevideo: Fundación de Cultura Universitaria, 187 pp.

- Ermida Uriarte, Óscar (1999) La Flexibilización de la Huelga. Montevideo: Fundación de Cultura Universitaria, 55 pp.

- Ermida Uriarte, Óscar (2011) "Crítica de la Libertad Sindical". Derecho Laboral, $\mathrm{N}^{\circ} 242$, pp. 225-253.

- Gamonal Contreras, Sergio (2000). "La Constitución de 1980 y la Libertad Sindical”. Anuario de Derecho del Trabajo y Seguridad Social, No 1, Sociedad Chilena de Derecho del Trabajo y de la Seguridad Social, pp. 69-97.

- Gamonal Contreras, Sergio (2011) Derecho Colectivo del Trabajo. $2^{a}$ edición. Santiago de Chile: Abeledo Perrot, 521 pp.

- Gernigon, Bernard; Odero, Alberto y Guido, Horacio (1998) Principios de la OIT sobre el Derecho de Huelga. Ginebra: Oficina Internacional del Trabajo, 64 pp., p. 8.

- Giugni, Gino (1997) Diritto Sindacale, Bari: Cacucci, 302 pp.

- Irureta Uriarte, Pedro (2006). Constitución y Orden Público Laboral. Un análisis del art. $19 N^{\circ} 16$ de la Constitución chilena. Colección Investigaciones Jurídicas No 6. Santiago de Chile: Universidad Alberto Hurtado, 234 pp.

- Kahn-Freund, Otto (1987) Trabajo y Derecho. Traducción de Jesús M. Galiana Moreno. Madrid: Ministerio de Trabajo y Seguridad Social, $482 \mathrm{pp}$. 
- Klare, Karl (1994). "Abbigliamento e potere: Il controllo sull'aspetto del lavoratore subordinato". Giornale di Diritto del Lavoro e di Relazioni Industriali, N 63, pp. 567-626.

- Leader, Sheldon (2009-2010). "Can You Derive a Right to Strike from the Right to Freedom of Association?”. Canadian Labour \& Employment Law Journal, 15, pp. 271-295.

- Macchiavello Contreras, Guido (1989) Derecho Colectivo del Trabajo. Santiago de Chile: Editorial Jurídica de Chile, 548 pp.

- Medina Quiroga, Cecilia (1996). "Introducción: El Derecho Internacional de los Derechos Humanos". En Medina Quiroga, Cecilia y Mera Figueroa, Jorge (editores): Sistema Juridico y Derechos Humanos, $\mathrm{N}^{\circ} 6$ serie publicaciones especiales. Santiago de Chile: Escuela de Derecho Universidad Diego Portales, pp. 27-84.

- Mengoni, Luigi (1985). "Gruppi organizzati e mediazioni dei conflitti”. En Diritto e Valori. Bolonia: Il Mulino, pp. 307-332.

- Mill, John Stuart (1943) Principios de Economía Politica. Traducción de la Edición Ashley de 1909 (la séptima edición de 1871 fue la última corregida por Mill) de Teodoro Ortiz. México: Fondo de Cultura Económica, 1031 pp.

- Naimoli, Simona (2008). "Individuale e collettivo in materia di sciopero alle origini del diritto del lavoro". En Loffredo, Antonio (editor): La Titolaritá del Diritto di Sciopero. Bari: Cacucci, pp. 107116.

- Nogueira Alcalá, Humberto (2001). "Las Constituciones y los Tratados en materia de Derechos Humanos: América Latina y Chile". Revista de Derecho Público, Vol. 63, pp. 115-162.

- Nogueira Alcalá, Humberto (2009) Derechos Fundamentales y Garantias Constitucionales. Tomo 3, Derechos Sociales Fundamentales. Santiago de Chile: Centro de Estudios Constitucionales de Chile, Universidad de Talca y Librotecnia, 604 pp.

- Novitz, Tonia (2003) International and European Protection of the Right to Strike. Nueva York: Oxford University Press, 419 pp.

- Palma Ramalho, María do Rosario (2000) Da Autonomia Dogmática do Directo do Trabalho. Coimbra: Almedina, 1139 pp.

- Pierri, Maurizia (2008) Lo Sciopero nella Democrazia Deliberativa. San Cesario di Lecce: Pensa Editore, 125 pp.

- Pizzuti, Paolo (2010) Sciopero Articolato e Prestazioni Improduttive. 2a edición. Roma: Aracne Editrice, 207 pp.

- Radé, Christophe (1997) Droit du Travail et Responsabilité Civile. París: LGDT, 397 pp.

- RÉmy, Patrick (1998). "Le Contenu de la Liberté de Coalition dans la Constitucion Allemande". Bulletin de Droit Comparé du Travail 
et de la Sécurité Social, Université Montesquieu - Bordeaux IV, COMPTRASEC, pp. 84-116.

- Rodríguez-Piñero y Bravo Ferrer, Miguel y Villavicencio Ríos, Alfredo (1995). "La Libertad Sindical en las Constituciones Latinoamericanas". En Ermida Uriarte, Óscar y Ojeda Avilés, Antonio (coordinadores): El Derecho Sindical en América Latina. Montevideo: Fundación de Cultura Universitaria, pp. 11-38.

- Romagnoli, Umberto (2008). "Sobre el despido o la Violencia del Poder Privado". Revista de Derechos Social Latinoamérica, Nos 4-5, pp.9-15.

- Saiz Arnaiz, Alejandro (1999) La Apertura Constitucional al Derecho Internacional y Europeo de los Derechos Humanos. El artículo 10.2 de la Constitución Española. Madrid: Consejo General del poder Judicial, 302 pp.

- Sánchez Martínez, M. Olga (1997) La Huelga ante el Derecho. Conflictos, valores y normas. Madrid: Dykinson, $326 \mathrm{pp}$.

- Scelle, Goerges (1922) Le Droit Ouvrier. París: Librairie Armand Colin, 210 pp.

- Silva Bascuñán, Alejandro (2010) Tratado de Derecho Constitucional. Tomo XIII. Santiago de Chile: Editorial Jurídica de Chile, 438 pp.

- Sinzheimer, Hugo (1984) Crisis Económica y Derecho del Trabajo. Traducción de Felipe Vázquez Mateo. Madrid: Instituto de Estudios Laborales y de la Seguridad Social, 131 pp.

- Tapia Guerrero, Francisco (2005) Sindicatos en el derecho chileno del trabajo. Santiago de Chile: LexisNexis, 449 pp.

- Tucker, Eric (2012). "Labor's Many Constitutions (And Capital's Too)". Comparative Labor Law \& Policy Journal, Vol. 33, pp. 355377.

- Vallebona, Antonio (2007) Le Regole dello Sciopero nei Servizi Pubblici Essenziali. Turín: Giappichelli, 197 pp.

- Veneziani, Bruno (1992) Stato e autonomia collettiva, diritto sindacale italiano e comparato. Bari: Cacucci, $501 \mathrm{pp}$.

- Verdugo, Mario; Pfeffer, Emilio y Nogueira, Humberto (1999) Derecho Constitucional. Tomo I, 2a edición actualizada. Santiago de Chile: Editorial Jurídica de Chile, 375 pp.

- Villavicencio Ríos, Alfredo (2007) La Libertad Sindical en las Normas y Pronunciamientos de la OIT: sindicación, negociación colectiva y huelga. Montevideo: Fundación de Cultura Universitaria, $92 \mathrm{pp}$.

- Vivanco, Ángela (2006) Curso de Derecho Constitucional. Aspectos Dogmáticos de la Carta Fundamental de 1980. Tomo II. Santiago de Chile: Ediciones Universidad Católica de Chile, 555 pp. 
- White, Stuart (1998). "Trade Unionism in a Liberal State". En Gutmann, Amy (editor): Freedom of Association. Princeton: Princeton University Press, pp. 330-356.

- White, Stuart (2012). "Liberal Neutrality and Trade Unions". Comparative Labor Law \& Policy Journal, Vol. 33, pp. 417-426. 